\title{
Design and preliminary recruitment results of the Cluster randomised triAl of PSA testing for Prostate cancer (CAP)
}

E L Turner ${ }^{\star}, 1$, C Metcalfe ${ }^{1}$, J L Donovan ${ }^{1}$, S Noble$^{1}$, J A C Sterne ${ }^{1}, \mathrm{~J}$ A Lane ${ }^{1}, \mathrm{~K}$ N Avery ${ }^{1}$, L Down ${ }^{1}, \mathrm{E} \mathrm{Walsh}{ }^{1}$,

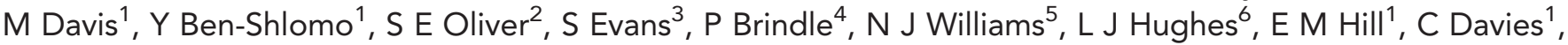
S Y Ng${ }^{7}, \mathrm{D} \mathrm{E} \mathrm{Neal^{6 }}$, F C Hamdy ${ }^{8}$, R M Martin ${ }^{1,9}$ and the CAP trial group

${ }^{1}$ School of Social and Community Medicine, University of Bristol, Canynge Hall, 39 Whatley Road, Bristol BS8 2PS, UK; ${ }^{2}$ Department of Health Sciences, University of York and the Hull York Medical School, York YO10 5DD, UK; ${ }^{3}$ Royal United Hospital Bath, Combe Park, Bath BA1 3NG, UK; ${ }^{4}$ Avon Primary Care Research Collaborative, Marlborough Street, South Plaza, Bristol BS1 $3 N X, U K ;{ }^{5}$ School of Social and Community Medicine, University of Bristol, Royal Hallamshire Hospital, Sheffield S10 2JF, UK; ${ }^{6}$ Department of Oncology, University of Cambridge, Box 279 (S4), Addenbrooke's Hospital, Cambridge CB2 0QQ, UK; ${ }^{7}$ School of Social and Community Medicine, University of Bristol, Freeman Hospital, High Heaton, Newcastle upon Tyne NE7 7DN, UK; ${ }^{8}$ Nuffield Department of Surgical Sciences, John Radcliffe Hospital, Oxford OX3 9DU, UK and ${ }^{9} \mathrm{MRC} /$ University of Bristol Integrative Epidemiology Unit, University of Bristol, Oakfield House, Oakfield Grove, Bristol BS8 2BN, UK

Background: Screening for prostate cancer continues to generate controversy because of concerns about over-diagnosis and unnecessary treatment. We describe the rationale, design and recruitment of the Cluster randomised triAl of PSA testing for Prostate cancer (CAP) trial, a UK-wide cluster randomised controlled trial investigating the effectiveness and cost-effectiveness of prostate-specific antigen (PSA) testing.

Methods: Seven hundred and eighty-five general practitioner (GP) practices in England and Wales were randomised to a population-based PSA testing or standard care and then approached for consent to participate. In the intervention arm, men aged 50-69 years were invited to undergo PSA testing, and those diagnosed with localised prostate cancer were invited into a treatment trial. Control arm practices undertook standard UK management. All men were flagged with the Health and Social Care Information Centre for deaths and cancer registrations. The primary outcome is prostate cancer mortality at a median 10-yearfollow-up.

Results: Among randomised practices, 271 (68\%) in the intervention arm (198114 men) and 302 (78\%) in the control arm (221929 men) consented to participate, meeting pre-specified power requirements. There was little evidence of differences between trial arms in measured baseline characteristics of the consenting GP practices (or men within those practices).

Conclusions: The CAP trial successfully met its recruitment targets and will make an important contribution to international understanding of PSA-based prostate cancer screening.

Annually, over 500000 men worldwide are diagnosed with prostate cancer, which is rapidly becoming the most common male cancer, due to an ageing population and increased detection through serum prostate-specific antigen (PSA) testing. However, the aetiology of prostate cancer is poorly understood and there are limited prospects for primary prevention (Frankel et al, 2003). Serum PSA testing followed by transrectal ultrasound-guided needle biopsy identifies cancers localised to the prostate gland, and

*Correspondence: Dr EL Turner; E-mail: emma.turner@bristol.ac.uk

Received 20 September 2013; revised 8 April 2014; accepted 10 April 2014; published online 27 May 2014

(c) 2014 Cancer Research UK. All rights reserved 0007-0920/14 
could form the basis of a screening programme to detect disease amenable to cure. However, since many potentially identifiable prostate cancers are indolent (Sakr et al, 1996), over-diagnosis and over-treatment (Donovan, 2012; Sandhu and Andriole, 2012), which can impact adversely on a man's quality of life, are major concerns (Neal et al, 2009).

Two recently published randomised controlled trials of PSAbased screening (Andriole et al, 2009; Schroder et al, 2009) failed to resolve the controversy over the effectiveness of screening in reducing mortality and improving quality of life (Neal et al, 2009). In the primary analysis of the European Randomised Study of Screening for Prostate Cancer (ERSPC), a 20\% reduction in prostate cancer mortality was observed after a median follow-up of 9 years, with PSA testing every 4 years vs no screening (Schroder et al, 2009). The effect estimates were imprecise, however, with the 95\% confidence limits indicating that the benefit could be as much as $35 \%$ or as little as $2 \%$. The absolute reduction in risk suggested that 1410 men would need to be screened and 48 cancers detected to prevent one death from prostate cancer at approximately 8 years following diagnosis. A further analysis with median follow-up of 11 years (Schroder et al, 2012) yielded a similar $21 \%$ relative reduction in prostate cancer mortality and a slightly improved absolute benefit (1055 men would need to be screened and 37 cancers detected to prevent one death from prostate cancer). A microsimulation study based on ERSPC data suggested that $43 \%$ of cancers detected by screening are overdiagnosed and that the mortality benefits are diminished by a $23 \%$ reduction in quality-adjusted life-years because of the adverse effects of treatment (Heijnsdijk et al, 2012).

The PLCO (prostate, lung, colon and ovarian cancer screening) trial reported no mortality benefit from screening after 7 (Andriole et al, 2009) or 13 years (Andriole et al, 2012) of follow-up. However, there are relatively few prostate cancer deaths reported to date. In addition, high levels of non-compliance in the intervention arm and contamination by widespread PSA testing in the control arm, make it unlikely that the PLCO trial can accurately estimate the magnitude of the intervention effect (Gulati et al, 2012).

A recently updated Cochrane review (Ilic et al, 2011) of five randomised controlled trials, a meta-analysis (Djulbegovic et al, 2010) of six randomised controlled trials, including the ERSPC, PLCO and 20-year-follow-up of a small, long-term trial (Sandblom et al, 2011) do not provide strong evidence that screening causes reductions in allcause or prostate cancer-specific mortality that are important enough to outweigh potential harms. The recent updated report from the US Preventive Services Task Force recommended against routine PSAbased screening (Chou et al, 2011). However, the controversy surrounding these draft recommendations (Brett and Ablin, 2011; McNaughton-Collins and Barry, 2011) suggests continuing concerns about the methodological quality of some evidence and associated risks of bias. These concerns are reinforced by favourable modelling projections (Gulati et al, 2011) and secondary analyses (Roobol et al, 2009); thus, the benefits and harms of population or targeted prostate cancer screening remain uncertain.

The most effective treatment for PSA-detected localised prostate cancer is also unknown because treatment within published screening trials was not randomised, and published treatment trials are difficult to interpret in relation to screening and the known heterogeneity of the disease. The findings from the SPCG- 4 trial (comparing radical surgery and watchful waiting) provide robust evidence of a reduction in prostate cancer mortality in those assigned to radical surgery, but few men were recruited by PSA testing (Holmberg et al, 2012). The PIVOT trial did not provide conclusive evidence that older men with higher risk tumours (mean age 67 years, 48\% Gleason 7 or higher, $66 \%$ intermediate/high risk) benefit from radical surgery compared with observation (Wilt, 2012). Neither trial has clear application for younger men with predominantly low-risk tumours in contemporary PSA-detected cohorts.
Here, we report the design, methods and results of recruitment in the CAP (Cluster randomised triAl of testing for Prostate cancer) trial. CAP is a nationwide, primary care-based cluster RCT that evaluates whether PSA testing of men aged 50-69 years will reduce prostate cancer mortality and be cost-effective (ISRCTN92187251). The embedded ProtecT trial (Donovan et al, 2003; Lane et al, 2010) (ISRCTN20141297) compares the effectiveness and cost-effectiveness of radical prostatectomy, radical conformal radiotherapy and active monitoring (regular PSA testing and treatment review) in men with PSA-detected clinically localised prostate cancer. The CAP trial will estimate the effect of a policy to invite men aged 50-69 years for PSA testing.

\section{MATERIALS AND METHODS}

Study design. CAP is a pragmatic cluster RCT, testing effectiveness in everyday practice by comparing an invitation to attend for population-based PSA testing for prostate cancer (the ProtecT trial intervention arm) with standard UK National Health Service (NHS) care (control arm) in men aged 50-69 years registered with general practices (community-based primary care clinics) in and around eight cities in England and Wales: Birmingham, Bristol, Cambridge, Cardiff, Leeds, Leicester, Newcastle and Sheffield (Figure 1).

Cluster randomisation. General practitioner (GP) practices (the cluster unit) were randomised between 2001 and 2007 by a statistician not otherwise involved in the study before their recruitment ('Zelen' design (Zelen, 1979)). Randomisation was blocked and stratified by geographical area based on groups of 10-12 neighbouring practices and using a computerised random number generator to allocate a near-equal number of practices in each stratum to intervention and comparison arms. Where a stratum contained an odd number of practices, the greater number of practices was randomised to the intervention arm to support recruitment to the embedded ProtecT treatment trial.

Recruitment of GP practices. Randomised practices were contacted by a researcher who briefed the GPs primary care doctors and practice managers, following which an information and consent pack was sent, tailored to the allocated arm. A senior partner (or equivalent) was asked to provide written consent for participation in the study, acting as a 'guardian' of the interests of individuals currently registered at the practice who would be involved in the study. Practices who contemporaneously recruited men to a trial of rofecoxib in the prevention of prostate cancer (Vioxx in Prostate Cancer Prevention study (www.clinicaltrials. gov/show/NCT00060476) were excluded. Control arm practices within clusters where no intervention arm practices were recruited,

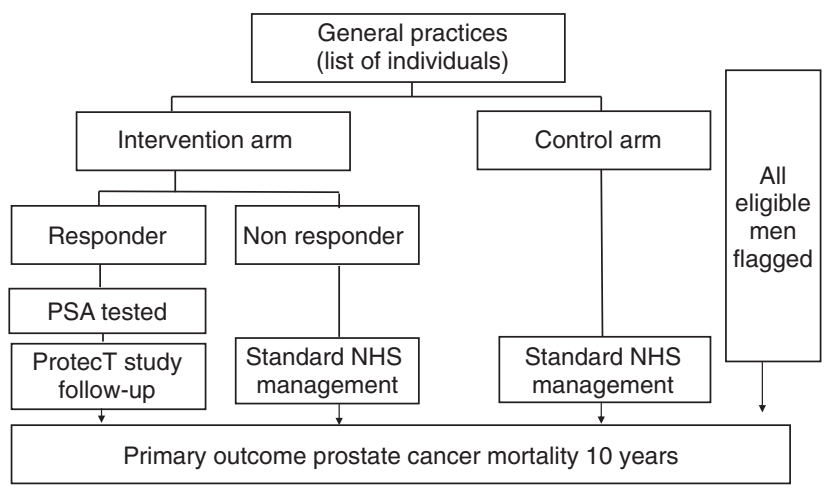

Figure 1. Trial design. 
and intervention arm practices in clusters where no control arm practices were recruited, were also excluded.

The success of randomisation and the impact of post-randomisation exclusions or dropouts were assessed by comparing routinely available practice level variables between the trial arms: list size; index of multiple deprivation (IMD) scores at lower level super output area (IMD England and Wales, 2011) based on practice postcode; urban-rural classification (Urban Rural Classification ONS, 2011); and mean prevalence of cancer, diabetes, obesity and coronary heart disease, based on data routinely submitted to the NHS Quality Outcomes Framework by GP practices (Quality Outcomes Framework (QOF) 2007/08, 2011).

Recruitment of participants. Recruitment to the intervention arm has been described in detail elsewhere (Donovan et al, 2002; Lane et al, 2010). Briefly, in each intervention arm practice, men aged 50-69 years were identified from the computerised patient lists on a specific date (Lane et al, 2010) (the 'list date'). Each man was sent a single invitation by letter to attend a nurse-led prostate-check clinic appointment where the potential benefits and harms of having a PSA test were explained, and written informed consent was obtained. There was a second consent form completed after $24 \mathrm{~h}$ for all men who agreed to PSA testing. Men who attended the prostate-check clinic were also asked whether they would consent to being traced and flagged for vital status follow-up with the Health and Social Care Information Centre (HSCIC).

In control arm practices, all men aged 50-69 years registered with each practice on a pre-specified date (consistent with the list dates in intervention arm practices within the same stratum) were eligible for inclusion. Men were not individually invited to participate as they were undergoing standard NHS management. However, they (and intervention arm non-responders) were given the opportunity to opt out of follow-up with the HSCIC through information provided at each practice.

Lists of all men aged 50-69 years who were registered at the intervention and control arm practices on the 'list dates', and who had not opted out, were obtained through each practice computer system and the following data were extracted: name, postcode, date of birth, NHS number and practice identification number. These data were encrypted and returned to the co-ordinating centre (School of Social and Community Medicine, University of Bristol). These lists constitute the CAP trial cohort for follow-up.

Trial interventions. In the intervention arm, men with a raised PSA ( $\geqslant 3.0 \mathrm{ng} \mathrm{ml}^{-1}$ ) were invited for diagnostic tests including a transrectal ultrasound (TRUS)-guided biopsy. All men subsequently diagnosed with clinically localised prostate cancer (T1-T2, NX, M0) were asked to consider randomisation within the ProtecT three-arm trial of treatments: radical prostatectomy, radical conformal radiotherapy and active monitoring (regular PSA testing and review). If randomisation was unacceptable, a patient preference treatment option was agreed (Donovan et al, 2002; Lane et al, 2010). Men found to have advanced disease were treated in the NHS urology clinics of the recruiting centres. All men treated via randomisation or by preference were followed up in annual nurse-led clinics.

Control arm practices were supplied with contemporary information from the NHS prostate cancer-risk management programme (NHS, 2011) to encourage standard NHS management, including the provision of standardised information about the potential benefits and harms of PSA testing for any man over the age of 50 years who requested a PSA test.

Follow-up and identification of a prostate cancer-related event. Surveillance for relevant outcomes is passive, triggered by the occurrence of death or cancer registration identified via flagging with the HSCIC. When such triggers are received, clinical and resource-use data from the man's medical records are obtained, blind to the cancer registry or death certificate information.
Data items include: symptoms and signs of prostate cancer presence and progression; diagnostic and monitoring tests; histology, tumour stage; treatments received and the outcomes of treatment; complications related to prostate cancer diagnosis or treatment; co-morbidities; and other resource-use data (e.g., length of inpatient stay, outpatient appointments). For men who have died, a researcher, blind to information on the death certificate, prepares a short-structured vignette that summarises the key clinical events from diagnosis to death.

Determination of cause of death. To minimise potential attribution bias (Albertsen et al, 2000; Black et al, 2002), an international Cause of Death Evaluation (CODE) Committee reviews clinical information abstracted from medical records (vignettes) on all possible prostate cancer deaths in both arms of the trial (independent chair: professor Peter Albertsen, Connecticut, USA). A list of specific ICD9 and ICD10 codes, adapted from those used by the PLCO Screening Trial (Miller et al, 2000), is used to identify a possible prostate cancer event from the ICD codes listed in parts I and II of each man's death certificate. The following outcomes are assigned by the reviewers (blind to trial arm and information on the death certificate), according to predefined definitions adapted from those used in the ERSPC trial (de Koning et al, 2003): definite, probable, possible, unlikely or definitely not prostate cancer; and definite or probable intervention-related mortality. Further information about the CODE process and algorithm will be published separately.

Primary and secondary outcome measures. The primary outcome is 'definite' or 'probable' prostate cancer mortality after a median 10-year-follow-up, which will occur in 2016. Secondary outcomes include all-cause mortality at median follow-up of 10 and 15 years; definite or probable prostate cancer mortality at 15 years; disease status and staging; and cost-effectiveness. Sensitivity analyses will restrict prostate cancer mortality to deaths classified as definite prostate cancer and widen the definition to include definite, probable and possible prostate cancer deaths. The impact of PSA testing on health-related quality of life has been investigated in a linked study (Avery et al, 2008a,b; Macefield et al, 2010).

Assessment of contamination. The level of PSA testing from a convenient sample of 87 control arm general practices in 2007 was collected using the EMIS LV computer system. Information for a total of 126716 men aged 45-89 years with no recorded diagnosis of prostate cancer before 1 January 2007 was collected and has been reported previously (Williams et al, 2011). Further studies of contamination are underway.

Ethics and research governance. Men who attended the prostatecheck clinic in the intervention arm gave individual informed consent (Trent MREC/01/4/025). Approval for flagging of men in the control arm and non-responders in the intervention arm was obtained under Section 251 of the NHS Act 2006 (PIAG 4-09 (k)/2003) from the UK Patient Information Advisory Group (PIAG) (which became until recently the National Information Governance Board Ethics and Confidentiality Committee, NIGBECC). Trent MREC provided ethics approval for flagging (MREC/03/4/093) and review of the medical records of men with prostate cancer (05/MRE04/78). Men who were alive when we were notified of a prostate cancer diagnosis provided individual informed consent for review of their medical records. PIAG/NIGBECC approval allows review of the medical records of men who died of a cause potentially related to prostate cancer before consent could be gained (provided the man did not record an objection to their medical records being used for research while alive) (PIAG 1-05(f)/2006). All clinical centres have local research governance and ethics approval. The CAP study is sponsored by the University of Bristol and funded by Cancer Research UK and the Department of Health. 
Analysis plan. The primary analysis will be by intention-to-screen: all men followed up in the intervention arm will be included in that arm for analysis regardless of whether or not they responded to the invitation to have a PSA test. Similarly, control arm men will be included in that arm regardless of whether they had a PSA test. The effect of an invitation to screening on prostate cancer mortality will be estimated as a rate ratio while allowing for clustering by general practice once a median of 10 years follow-up data has accumulated. Analyses will be adjusted for randomisation strata.

Follow-up will commence on the 'list date' for each practice. Men will be excluded from the analyses if they had prevalent prostate cancer (diagnosed at or before the list date). Men will be censored on the date of death, or date of loss to follow-up (e.g., notified by the HSCIC as having emigrated). This approach to analysis will be adapted to the secondary outcome measure, such as all-cause mortality. Sensitivity analyses will assess whether controlling for any baseline imbalances in practice characteristics makes any difference to the estimated effects of screening.

If any of the three treatment arms in the ProtecT trial is superior (leads to lower mortality compared with the other arms), differences in prostate cancer or all-cause mortality between the CAP trial arms may be smaller than would be expected if a screening programme had used the optimal treatment(s). We will estimate the effect on mortality of such an 'optimal' screening programme, based on the (unbiased) treatment effect estimates from ProtecT and the (unbiased) overall effect estimates from CAP. Similar to what has been done for the ERSPC study (Roobol et al, 2009), we will use appropriate methods to estimate the effect of testing in those who undergo PSA measurement (complier average causal effect). This can be used to predict the overall effect of a screening programme under different assumptions about uptake of PSA testing and subsequent treatment.

Sample size and power. The sample size of the CAP trial was determined by the number of practices required to meet the recruitment target for the embedded Protect trial. Power calculations assessed whether this would be sufficient to detect reductions in prostate cancer mortality of a magnitude likely to be important to the NHS (Gohagan et al, 1994; Auvinen et al, 1996). We considered a range of plausible between-practice coefficients of variation (a measure of the amount of between-practice variation in prostate cancer mortality rates). For example, based on estimates of the incidence of prostate cancer mortality (the primary outcome) over 10 years using 2006 England and Wales incidence and mortality data (Office for National Statistics (ONS), 2008), and assuming a plausible coefficients of variation of 0.2, 209000 men in each study arm allows a true overall prostate cancer mortality rate ratio of 0.87 to be detected with $80 \%$ power at $5 \%$ significance. This corresponds to an intervention rate ratio among men undergoing screening (IRR) from 0.62 to 0.73 , assuming uptake of the invitation to PSA testing of $35 \%$ and $50 \%$, respectively. These IRRs are similar to those assumed in the power calculations for the ERSPC trial (de Koning et al, 2002), where post-consent randomisation ensured most men would undergo testing. Our estimates of the impact of a range of PSA contamination rates (defined as ever having a PSA test during follow-up, as in ERSPC (de Koning et al, 2002)), suggest that the effect of contamination is minimal unless it reaches $20 \%$, a level unlikely in this trial (Williams et al, 2011).

\section{RESULTS}

\section{Recruitment}

GP practice recruitment. In total, 911 GP practices were randomised in 99 geographical areas. Six areas (52 practices) were excluded from further analysis as no intervention or control arm practices were recruited (see Figure 2). Of the 440 practices in the intervention arm and 419 in the control arm, 42 and 32 (respectively) were ineligible, because the GP practice was involved in the Vioxx trial, had ceased to exist, consented too late to allow participation, exclusively covered an atypical population (e.g., private, asylum seekers, children in care, homeless, sheltered housing), could not produce a list of men aged 50-69, or had been randomised in error (i.e., practices that participated in the feasibility phase of the Protect trial (Donovan et al, 2003)). Of the remaining 398 intervention arm and 387 control practices, 42 and 40, respectively, explicitly refused to participate, while 85 and 45, respectively had not responded after being allowed at least one year to consider taking part (and can be considered as implicit refusals, generated by the way the study was carried out). There was little evidence of differences between measured characteristics of the 573 participating practices and the 130 implicit refusal practices (list size 6827 vs $7264(P=0.4)$; IMD English 29 vs 27 $(P=0.3)$; IMD Wales 21 vs $23 \quad(P=0.8)$; number of urban practices $88 \%$ vs $82 \%(P=0.07)$; cancer prevalence $0.55 \%$ vs $0.54 \% 9(P=0.7)$; diabetes prevalence $3.7 \%$ vs $3.6 \%(P=0.7)$; obesity prevalence $7.9 \%$ vs $8.5 \%(P=0.08)$; coronary heart disease $4 \%$ vs $3.8 \%(P=0.2)$, respectively). Where practices explicitly refused, the major reasons were lack of interest, time or space (Down et al, 2009). Thus, among the eligible practices, $271(68 \%)$ in the intervention arm and $302(78 \%)$ in the control arm consented to participate.

We found little evidence of differences between the measured characteristics between the 785 eligible practices randomised to the intervention compared with control arms. Neither did we find evidence of differences in measured characteristics between the practices who consented to participate in the intervention compared with control arms (Table 1).

Take-up of PSA testing. Among 197925 eligible men in the intervention arm, 16752 were not invited for a PSA test because they met ProtecT study exclusion criteria (they were excluded by their GP because of terminal or severe mental illness, serious co-morbidity or pre-existing prostate cancer diagnosis). However, these men are included in the follow-up for prostate cancer incidence and mortality via the HSCIC. A further 1404 men were excluded as they had prevalent prostate cancer and the HSCIC could not trace 47 men, these figures are subject to change as a result of continued updates from the HSCIC. Of the remaining 179722 men who received an invitation to PSA testing within the intervention arm, 79989 (45\%) attended a prostate-check clinic and 65113 (36\%) men gave full consent for their PSA level to be measured as part of the ProtecT study.

In the control arm among 221629 men, three men opted out, 1632 had prevalent prostate cancer and HSCIC failed to trace 81 , as above these figures are subject to change upon receipt of further information from the HSCIC. Thus, a total of 416387 men were randomised into the intervention and control arms (Figure 2), a population-based sample covering approximately $8 \%$ of the England and Wales male population aged 50-69 years (Quality Outcomes Framework (QOF) 2007/08, 2011). Consent rates for flagging with the HSCIC were over $99 \%$, and $97.5 \%$ of men were matched to the NHSCR database automatically with $2.5 \%$ requiring manual matching. There were no substantial differences between the men in the intervention and control arms in terms of age (mean 59.1), baseline prevalence of prostate cancer (prostate cancer diagnosed before randomisation was $0.71 \%$ in the intervention arm compared with $0.74 \%$ in the control arm) or index of multiple deprivation score, a census-derived measure of multiple aspects of area-level deprivation, in England (22.9) or Wales (20.8 vs 19.6, respectively). 


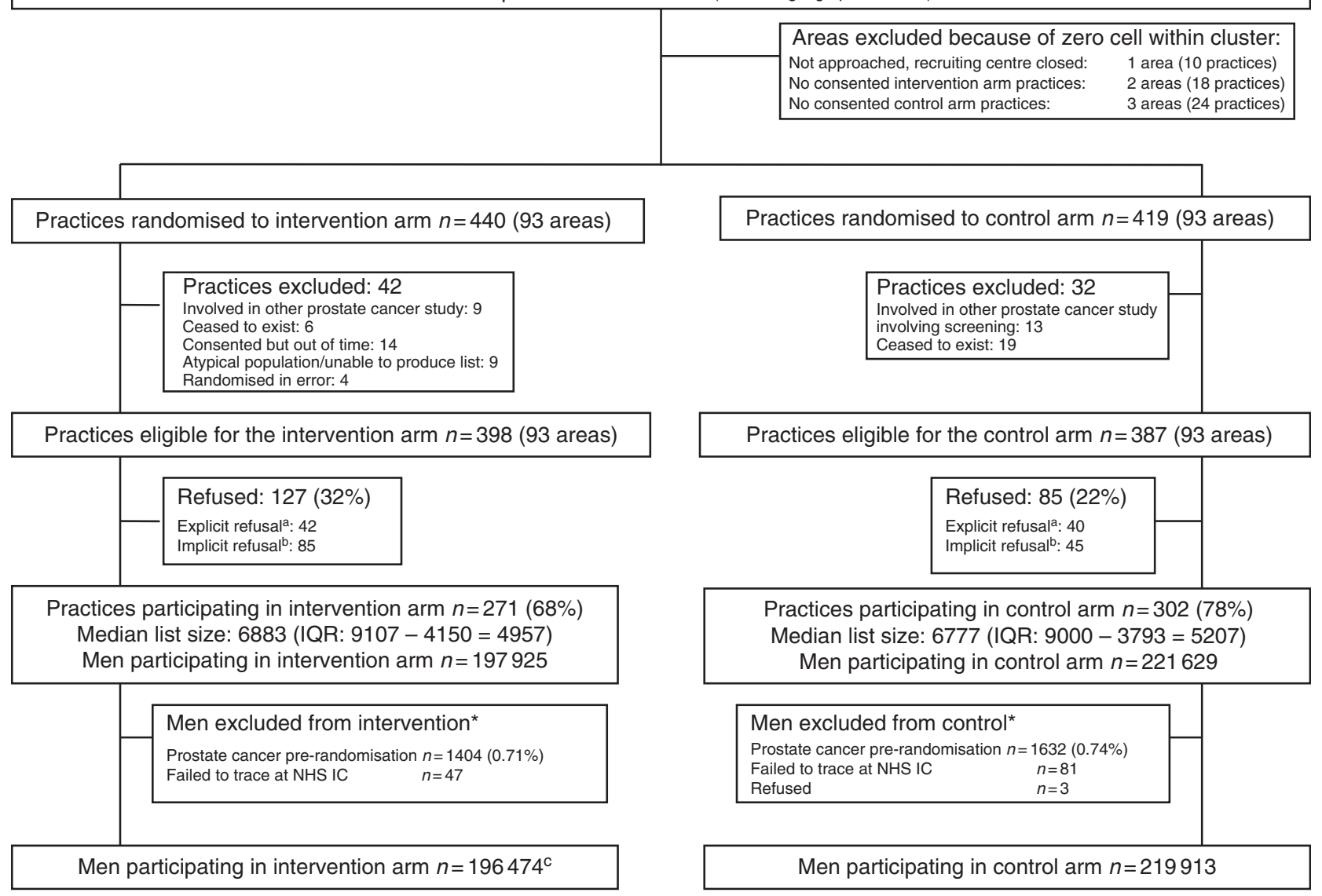

Figure 2. Consort diagram for recruitment into the Cluster Randomised Trial of Testing for Prostate Cancer (CAP), England and Wales. ${ }^{a}$ Explicit refusal $=$ refused to participate. ${ }^{b}$ Implicit refusal $=$ no definitive response given to invitation to participate. ${ }^{\mathrm{C}}$ Includes $n=6581$ pseudo-anonymised follow-up for mortality and prostate cancer. *Figures as of June 2013, subject to small changes over time because of continued updates from the Health and Social Care Information Centre, eg, to remove newly identified duplicates or changes to trace status.

\section{DISCUSSION}

The CAP trial recruited successfully over 415000 men from 573 primary care practices across the UK. Its future contribution to the evidence base is illustrated by the ways in which it differs in methods of recruitment, screening and treatments offered compared with the two major published screening trials (summarised in Table 2; Schroder and Roobol, 2010). Cluster randomisation makes estimation of the effect of a policy to invite men for screening easier, enhancing the trial's generalisability beyond men consenting to individual randomisation. An 'intentionto-screen' analysis will ensure that individuals will be analysed in the arm their GP practice was allocated to, regardless of whether or not they received the intervention.

A major strength, not available to any of the other screening trials, is that the three-arm ProtecT trial will establish the relative effectiveness and cost-effectiveness of treatments for PSA-detected disease in men diagnosed with clinically localised prostate cancer, including a contemporary programme of active monitoring (Donovan, 2012), thus enabling the determination of the most effective and cost-effective treatment following PSA testing. ProtecT will assess how active monitoring compares with radical surgical and radiation therapy, and the balance of benefit to harm for these patients. Estimates of the effect on mortality of an 'optimal' screening programme will be provided based on the (unbiased) treatment effect estimates from the ProtecT trial of treatments and the (unbiased) overall effect estimates from CAP.
Cluster randomisation was used because PSA testing was offered to all men in intervention arm practices where individual randomisation would have been impracticable. Compared with an individually randomised design, the clustered design reduces the likelihood of contamination in the control group: only $6.2 \%$ of men (95\% confidence interval: 5.7-7.0\%; practice-based interquartile range 3.6-8.4\%) had their PSA tested in 2007 in a sample of control arm CAP practices (Williams et al, 2011), in line with published studies (2-9\% in any one year (Parker and Melia, 2005)). Further assessments of contamination are ongoing to estimate more precisely the proportion of control men undergoing one or more PSA tests during the 10-year study period.

Randomisation of general practices was carried out before consent to participate, because of logistical requirements related to the recruitment process in the ProtecT trial. Consent rates amongst eligible practices in the intervention and control arm were $68 \%$ and $78 \%$, respectively. We found little evidence of differences between the intervention and control arms at baseline at either an individual or practice level. It is not possible to exclude the possibility that post-randomisation exclusions introduced selection bias. Nonetheless, the large number of practices randomised and the stratified randomisation scheme should ensure that practices are approximately balanced with respect to potential prognostic factors at the time of randomisation. A further strength is that intervention and control arm men were traced and flagged with the HSCIC, ensuring an unbiased intention-to-screen analysis, comparing outcomes for the two arms of the trial according to the original random allocation. 
Table 1. Comparison of baseline characteristics between participating intervention and control arm practices, England and Wales

\begin{tabular}{|c|c|c|c|}
\hline & Intervention arm $(n=271)$ & Control arm $(n=302)$ & $P$-value for difference ${ }^{a}$ \\
\hline Mean practice list size (s.d.) & $6883(3442)$ & $6777(3707)$ & 0.7 \\
\hline Number of urban practices ${ }^{\mathbf{b}}(\%)$ & 267 (88\%) & $267(88 \%)$ & 0.8 \\
\hline \multicolumn{4}{|l|}{ Indicies of deprivation } \\
\hline $\begin{array}{l}\text { Mean IMD score }{ }^{c} \text { in England (s.d.) } \\
\text { Mean IMD score }{ }^{d} \text { in Wales (s.d.) }\end{array}$ & $\begin{array}{l}28(19) \\
21(14)\end{array}$ & $\begin{array}{l}30(19) \\
22(16)\end{array}$ & $\begin{array}{l}0.2 \\
0.7\end{array}$ \\
\hline \multicolumn{4}{|l|}{ Mean prevalence from QOF } \\
\hline $\begin{array}{l}\text { All cancers }{ }^{\mathbf{e}} \text { (s.e.) } \\
\text { Diabetes (s.e.) } \\
\text { Obesity (s.e.) } \\
\text { Coronary heart disease (s.e.) }\end{array}$ & $\begin{array}{c}0.57 \%(0.02 \%) \\
3.6 \%(0.07 \%) \\
8.0 \%(0.2 \%) \\
4.1 \%(0.09 \%)\end{array}$ & $\begin{array}{c}0.53 \%(0.01 \%) \\
3.7 \%(0.06 \%) \\
7.8 \%(0.2 \%) \\
3.9 \%(0.08 \%)\end{array}$ & $\begin{array}{l}0.07 \\
0.4 \\
0.3 \\
0.2\end{array}$ \\
\hline
\end{tabular}

Abbreviations: IMD = index of multiple deprivation; QOF = quality outcomes framework; s.d. = standard deviaton; s.e. = standard error.

${ }^{\text {a }}$-values were calculated using Robust Regression, all analyses adjusted for geographic and primary care grouping.

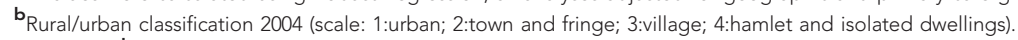

$\mathbf{c}_{2004}$ and ${ }^{\mathbf{d}_{2}} 2005$ (higher scores indicate greater levels of deprivation).

e Prevalence of cancer from quality outcomes framework 2004/5 where available ( $n=491)$

Table 2. Comparison of the major design characteristics of the Cluster randomised triAl of PSA testing for Prostate cancer, European Randomized Study of Screening for Prostate Cancer (ERSPC) and the Prostate, Lung, Colorectal and Ovary (PLCO) trials

\begin{tabular}{|c|c|c|c|}
\hline & $\begin{array}{l}\text { Cluster randomised triAl of } \\
\text { PSA testing for Prostate cancer }\end{array}$ & $\begin{array}{l}\text { European Randomized Study of Screening for } \\
\text { Prostate Cancer }\end{array}$ & $\begin{array}{l}\text { Prostate, Lung, Colorectal } \\
\text { and Ovary Trials }\end{array}$ \\
\hline Age range (years) & $50-69$ & $55-69$ (core group) Some 50-54, 70-74 & $55-74$ \\
\hline \multicolumn{4}{|l|}{ Randomisation } \\
\hline $\begin{array}{l}\text { Randomisation unit } \\
\text { Randomisation } \\
\text { process }\end{array}$ & $\begin{array}{l}\text { General practice } \\
\text { All men at participating general } \\
\text { practices were randomised } \\
\text { (population-based effectiveness trial) }\end{array}$ & $\begin{array}{l}\text { Individual } \\
\text { In Netherlands, Belgium, Switzerland, Spain, only men giving } \\
\text { consent underwent randomisation (efficacy trial).In Finland, } \\
\text { Sweden and Italy, all men identified from cancer registries } \\
\text { were randomised (population-based effectiveness trial) }\end{array}$ & $\begin{array}{l}\text { Individual } \\
\text { Only men giving informed } \\
\text { consent were randomised } \\
\text { (efficacy trial) }\end{array}$ \\
\hline \multicolumn{4}{|l|}{ Detection } \\
\hline $\begin{array}{l}\text { Prostate-specific } \\
\text { antigen threshold } \\
\text { Biopsy protocol } \\
\text { Screening interval }\end{array}$ & $\begin{array}{l}3.0 \mathrm{ng} \mathrm{ml}^{-1} \\
\text { 10-core transrectal ultrasound- } \\
\text { guided biopsy } \\
\text { Single screen }\end{array}$ & $\begin{array}{l}3.0 \mathrm{ng} \mathrm{ml}^{-1} \text { or } 4.0 \mathrm{ng} \mathrm{ml}^{-1} \text { (varies by centre) } \\
\text { Majority of centres used sextant biopsies guided by } \\
\text { transrectal ultrasound } \\
\text { 4-yearly (some } 2 \text { years) }\end{array}$ & $\begin{array}{l}4.0 \mathrm{ng} \mathrm{ml}^{-1} \\
\text { Diagnostic evaluation decided } \\
\text { by the patients and their } \\
\text { primary physicians. } \\
1 \text { year }\end{array}$ \\
\hline \multicolumn{4}{|c|}{ Treatment and outcome } \\
\hline $\begin{array}{l}\text { Treatment regimen } \\
\text { in screened group } \\
\text { Outcome } \\
\text { ascertainment }\end{array}$ & $\begin{array}{l}\text { Randomised (surgery, radiotherapy, } \\
\text { active monitoring) } \\
\text { Independent blinded adjudication } \\
\text { committee }\end{array}$ & $\begin{array}{l}\text { Variable usual care (radical advised) } \\
\text { Blinded committee (some centres death certification) }\end{array}$ & $\begin{array}{l}\text { Variable usual care (radical } \\
\text { advised) } \\
\text { Blinded reviewers (prostate } \\
\text { cancer-specific death) }\end{array}$ \\
\hline
\end{tabular}

The CAP trial aims to evaluate the impact of population-based PSA testing for prostate cancer-a test with acknowledged limited specificity (Holmstrom et al, 2009), imperfect sensitivity (15.2\% of men with a PSA level of $4.0 \mathrm{ng} \mathrm{ml}^{-1}$ or less biopsied at the end of follow-up in the Prostate Cancer Prevention Trial were diagnosed with prostate cancer, with high-grade cancers (at least Gleason 7) observed throughout this range of PSA values) (Thompson et al, 2004), and a high rate of over-diagnosis of lowrisk disease resulting in over-treatment. Currently, however, there are no alternative reliable screening methods. The modest PSA testing rate in the intervention arm reflects that achievable with a single invitation to eligible participants, but randomisation allows us to employ appropriate statistical methods (e.g., complier average causal effects, contamination-adjusted ITT (Sussman and Hayward, 2010)) to estimate the effect in those who undergo PSA testing (Cuzick et al, 1997; Roobol et al, 2009). This can be used to predict the overall effect of a screening programme under different assumptions about PSA uptake. We will not be able to measure quality of life in the men being followed up passively; however, a linked study has investigated the impact of PSA testing on health-related quality of life in men followed up in the intervention arm (Avery et al, 2008a,b; Macefield et al, 2010).

ERSPC (Schroder et al, 2009) and PLCO (Andriole et al, 2009) included various screening intervals, ranging from 2 to 4 years. Cancers identified in second and subsequent screening rounds 
tended to be small with favourable histological grading, and with a low probability (about 1 in 10) of becoming clinically important in the man's lifetime (Schroder et al, 2010). The CAP trial aims to assess the impact of single PSA testing, allowing the lifetime risk of developing clinically important prostate cancer amongst men initially screen negative to be quantified, and contributing natural history data to the debate on whether a single PSA measurement in middle age could be used to risk stratify men for further PSA testing and targeted treatment (Vickers et al, 2010). It is possible that a single screen may underestimate the potential long-term benefits of a PSA-testing programme with multiple rounds (Hanley, 2005), as investigated in the ERSPC and other trials, and might be considered difficult to implement in countries with established PSA-testing programmes. A single PSA test, however, is less likely to identify large numbers of clinically insignificant disease (Heijnsdijk et al, 2012). In the UK, a previously unscreened population, the pool of clinically significant disease will be larger than in a population already undergoing regular screening. The trial design, therefore, will determine the effectiveness of a single PSA test while minimising the negative public health consequences of identifying clinically insignificant disease.

Misattribution of cause of death (Albertsen et al, 2000; Black et al, 2002) is an important potential source of bias in trials with cancer-specific mortality as the primary end point. Small inaccuracies in attributing cause of death can have the potential to alter the results if misclassification is differential between study arms. To minimise misclassification of cause of death, possible prostate cancer deaths are reviewed by an independent international cause of death committee blinded to the trial arms, with an embedded quality assurance process to ensure the reliability of the vignettes and the decisions of the reviewers (data to be presented separately).

We are powered to detect an overall prostate cancer mortality rate ratio of 0.87 ( $13 \%$ relative reduction). Reductions in prostate cancer mortality of the order of $15-20 \%$ are likely to be important to the NHS. Although our estimates suggest the effect of contamination is minimal unless it reaches $20 \%$, the power of the trial will be reduced if men in the control practices are screened for prostate cancer ('contamination'). An advantage of the cluster randomised design is that contamination is likely to be less of a problem than would be the case if men were individually randomised, and hence were alerted to the possibility of being screened for prostate cancer.

The CAP and ProtecT trials have been designed and conducted to make a much awaited and crucial contribution in understanding the effectiveness and cost-effectiveness of prostate cancer screening, as well as directly informing international policy on testing and treatment of this common malignancy.

\section{ACKNOWLEDGEMENTS}

We acknowledge the contribution of the CAP trial group Investigators: RMM (lead PI), JLD (PI), DEN (PI), FCH (PI), ELT (trial co-ordinator), CM (statistician), JACS (statistician), SN (health economist). Research staff: EMH, SYN, NJW, LD (data manager), EW (data manager), Joanna Thorn (health economist), CD, LJH, Mari-Anne Rowlands, Lindsey Bell. Management committee: ELT (chair), RMM, JLD, CM, JACS, SN, YB-S, AL, SEO, PB, SE. Trial steering committee: Michael Baum (chair), Peter Albertsen, Tracy Roberts, Mary Robinson, Jan Adolfsson, David Dearnaley, Anthony Zeitman, Fritz Schröder, Tim Peters, Peter Holding, Teresa Lennon, Sue Bonnington, Malcolm Mason, Jon Oxley, RMM, JLD, DEN, FCH, ELT, JAL. Data monitoring committee: Lars Holmberg (chair), Robert Pickard, Simon Thompson, Usha Menon. Cause of death committee:
Peter Albertsen (chair), Colette Reid, Jon McFarlane, Jon Oxley, Mary Robinson, Jan Adolfsson, Michael Baum, Anthony Zeitman, Amit Bahl, Anthony Koupparis. Administrative staff: Marta Tazewell, Genevieve Hatton-Brown. We thank Pete Shiarly for the development of bespoke databases, all members of the ProtecT study research groups, the Cancer Registries and staff at the HSCIC and all the men who participated in this study Funding: The CAP trial is funded by Cancer Research UK and the UK Department of Health (C11043/A4286, C18281/A8145, C18281/A11326 and C18281/A15064) and the ProtecT trial is funded by the UK National Institute for Health Research, Health Technology Assessment Programme (HTA 96/20/99).

\section{REFERENCES}

Albertsen PC, Walters S, Hanley JA (2000) A comparison of cause of death determination in men previously diagnosed with prostate cancer who died in 1985 or 1995. J Urol 163: 519-523.

Andriole GL, Crawford ED, Grubb III RL, Buys SS, Chia D, Church TR, Fouad MN, Gelmann EP, Kvale PA, Reding DJ, Weissfeld JL, Yokochi LA, O’Brien B, Clapp JD, Rathmell JM, Riley TL, Hayes RB, Kramer BS, Izmirlian G, Miller AB, Pinsky PF, Prorok PC, Gohagan JK, Berg CD (2009) Mortality results from a randomized prostate-cancer screening trial. N Engl J Med 360: 1310-1319.

Andriole GL, Crawford ED, Grubb III RL, Buys SS, Chia D, Church TR, Fouad MN, Isaacs C, Kvale PA, Reding DJ, Weissfeld JL, Yokochi LA, O’Brien B, Ragard LR, Clapp JD, Rathmell JM, Riley TL, Hsing AW, Izmirlian G, Pinsky PF, Kramer BS, Miller AB, Gohagan JK, Prorok PC (2012) Prostate cancer screening in the randomized Prostate, Lung, Colorectal, and Ovarian Cancer Screening Trial: mortality results after 13 years of follow-up. J Natl Cancer Inst 104: 125-132.

Auvinen A, Rietbergen JB, Denis LJ, Schroder FH, Prorok PC (1996) Prospective evaluation plan for randomised trials of prostate cancer screening. The International Prostate Cancer Screening Trial Evaluation Group. J Med Screen 3: 97-104.

Avery KN, Blazeby JM, Lane JA, Neal DE, Hamdy FC, Donovan JL (2008a) Decision-making about PSA testing and prostate biopsies: a qualitative study embedded in a primary care randomised trial. Eur Urol 53: 1186-1193.

Avery KN, Metcalfe C, Blazeby JM, Lane JA, Neal DE, Hamdy FC, Donovan JL (2008b) Prostate-specific antigen testing and prostate biopsy: are selfreported lower urinary tract symptoms and health-related quality of life associated with the decision to undergo these investigations? BJU Int 102: 1629-1633.

Black WC, Haggstrom DA, Welch HG (2002) All-cause mortality in randomized trials of cancer screening. J Natl Cancer Inst 94: 167-173.

Brett AS, Ablin RJ (2011) Prostate-cancer screening-What the U.S. Preventive Services Task Force left out. N Engl J Med 365: 1949-1951.

Chou R, Croswell JM, Dana T, Bougatsos C, Blazina I, Fu R, Gleitsmann K, Koenig HC, Lam C, Maltz A, Rugge JB, Lin K (2011) Screening for prostate cancer: a review of the evidence for the U.S. Preventive Services Task Force. Ann Intern Med 155: 762-771.

Cuzick J, Edwards R, Segnan N (1997) Adjusting for non-compliance and contamination in randomized clinical trials. Stat Med 16: 1017-1029.

de Koning HJ, Blom J, Merkelbach JW, Raaijmakers R, Verhaegen H, Van VP, Nelen V, Coebergh JW, Hermans A, Ciatto S, Makinen T (2003) Determining the cause of death in randomized screening trial(s) for prostate cancer. BJU Int 92(Suppl 2): 71-78.

de Koning HJ, Liem MK, Baan CA, Boer R, Schroder FH, Alexander FE. ERSPC (2002) Prostate cancer mortality reduction by screening: power and time frame with complete enrollment in the European Randomised Screening for Prostate Cancer (ERSPC) trial. Int J Cancer 98: 268-273.

Djulbegovic M, Beyth RJ, Neuberger MM, Stoffs TL, Vieweg J, Djulbegovic B, Dahm P (2010) Screening for prostate cancer: systematic review and meta-analysis of randomised controlled trials. BMJ 341: c4543.

Donovan JL, Hamdy FC, Neal DE, Peters TJ, Oliver S, Brindle L, Jewell D, Powell P, Gillatt D, Dedman D, Mills N, Smith M, Noble S, Lane A (2003) Prostate testing for cancer and Treatment (ProtecT) feasibility study. Health Technol Assess 7: 1-42.

Donovan J, Mills N, Smith M, Brindle L, Jacoby A, Peters T, Frankel S, Neal D, Hamdy F (2002) Quality improvement report: Improving design and 
conduct of randomised trials by embedding them in qualitative research: ProtecT (prostate testing for cancer and treatment) study. Commentary: presenting unbiased information to patients can be difficult. BMJ 325: $766-770$.

Donovan JL (2012) Presenting treatment options to men with clinically localized prostate cancer: the acceptability of active surveillance/ monitoring. J Natl Cancer Inst Monogr 2012: 191-196.

Down L, Metcalfe C, Avery K, Noble S, Lane JA, Neal DE, Hamdy FC, Donovan JL (2009) Factors distinguishing general practitioners who more readily participated in a large randomized trial were identified. $J$ Clin Epidemiol 62: 67-73.

Frankel S, Davey Smith G, Donovan J, Neal D (2003) Screening for prostate cancer. Lancet 361: 1122-1128.

Gohagan JK, Prorok PC, Kramer BS, Cornett JE (1994) Prostate cancer screening in the prostate, lung, colorectal and ovarian cancer screening trial of the National Cancer Institute. J Urol 152: 1905-1909.

Gulati R, Mariotto AB, Chen S, Gore JL, Etzioni R (2011) Long-term projections of the harm-benefit trade-off in prostate cancer screening are more favorable than previous short-term estimates. J Clin Epidemiol 64: 1412-1417.

Gulati R, Tsodikov A, Wever EM, Mariotto AB, Heijnsdijk EA, Katcher J, de Koning HJ, Etzioni R (2012) The impact of PLCO control arm contamination on perceived PSA screening efficacy. Cancer Causes Control 23: 827-835.

Hanley JA (2005) Analysis of mortality data from cancer screening studies: looking in the right window. Epidemiology 16: 786-790.

Heijnsdijk EA, Wever EM, Auvinen A, Hugosson J, Ciatto S, Nelen V, Kwiatkowski M, Villers A, Paez A, Moss SM, Zappa M, Tammela TL, Makinen T, Carlsson S, Korfage IJ, Essink-Bot ML, Otto SJ, Draisma G, Bangma CH, Roobol MJ, Schroder FH, de Koning HJ (2012) Quality-of-life effects of prostate-specific antigen screening. $N$ Engl J Med 367: 595-605.

Holmberg L, Bill-Axelson A, Steineck G, Garmo H, Palmgren J, Johansson E, Adami HO, Johansson JE (2012) Results from the scandinavian prostate cancer group trial number 4: a randomized controlled trial of radical prostatectomy versus watchful waiting. J Natl Cancer Inst Monogr 2012: 230-233.

Holmstrom B, Johansson M, Bergh A, Stenman UH, Hallmans G, Stattin P (2009) Prostate specific antigen for early detection of prostate cancer: longitudinal study. BMJ 339: b3537.

Ilic D, O'Connor D, Green S, Wilt TJ (2011) Screening for prostate cancer: an updated Cochrane systematic review. BJU Int 107: 882-891.

IMD England and Wales (2011) http://neighbourhood.statistics.gov.uk/or http://wales.gov.uk/topics/statistics/theme/wimd.

Lane JA, Hamdy FC, Martin RM, Turner EL, Neal DE, Donovan JL (2010) Latest results from the UK trials evaluating prostate cancer screening and treatment: The CAP and ProtecT studies. Eur J Cancer 46: 3095-3101.

Macefield RC, Metcalfe C, Lane JA, Donovan JL, Avery KN, Blazeby JM, Down L, Neal DE, Hamdy FC, Vedhara K (2010) Impact of prostate cancer testing: an evaluation of the emotional consequences of a negative biopsy result. Br J Cancer 102: 1335-1340.

McNaughton-Collins MF, Barry MJ (2011) One Man at a Time-Resolving the PSA Controversy. N Engl J Med 365: 1951-1953.

Miller AB, Yurgalevitch S, Weissfeld JL (2000) Death review process in the Prostate, Lung, Colorectal and Ovarian (PLCO) Cancer Screening Trial. Control Clin Trials 21: 400S-406S.

Neal DE, Donovan JL, Martin RM, Hamdy FC (2009) Screening for prostate cancer remains controversial. Lancet 374: 1482-1483.

NHS (2011) NHS prostate cancer risk management programme. www.cancerscreening.nhs.uk/prostate/informationpack.html.

Office of National Statistics (ONS) (2008) 2006 Mortality statistics: deaths registered in 2006. England and Wales (Series DR_06). The Stationary Office: London.

Parker C, Melia J (2005) Prostate-specific antigen testing in healthy men: a U.K. perspective. Clin Oncol (R Coll Radiol) 17: 228-230.

Quality Outcomes Framework (QOF) 2007/08 (2011) http://www.ic.nhs.uk/ statistics-and-data-collections/supporting-information/audits-andperformance/the-quality-and-outcomes-framework/qof-2007/08/data-tables.
Roobol MJ, Kerkhof M, Schroder FH, Cuzick J, Sasieni P, Hakama M, Stenman UH, Ciatto S, Nelen V, Kwiatkowski M, Lujan M, Lilja H, Zappa M, Denis L, Recker F, Berenguer A, Ruutu M, Kujala P, Bangma CH, Aus G, Tammela TL, Villers A, Rebillard X, Moss SM, de Koning HJ, Hugosson J, Auvinen A (2009) Prostate cancer mortality reduction by prostate-specific antigen-based screening adjusted for nonattendance and contamination in the European Randomised Study of Screening for Prostate Cancer (ERSPC). Eur Urol 56: 584-591.

Sakr WA, Grignon DJ, Haas GP, Heilbrun LK, Pontes JE, Crissman JD (1996) Age and racial distribution of prostatic intraepithelial neoplasia. Eur Urol 30: $138-144$.

Sandblom G, Varenhorst E, Rosell J, Lofman O, Carlsson P (2011) Randomised prostate cancer screening trial: 20 year follow-up. BMJ 342: d1539.

Sandhu GS, Andriole GL (2012) Overdiagnosis of prostate cancer. J Natl Cancer Inst Monogr 2012: 146-151.

Schroder FH, Hugosson J, Roobol MJ, Tammela TL, Ciatto S, Nelen V, Kwiatkowski M, Lujan M, Lilja H, Zappa M, Denis LJ, Recker F, Berenguer A, Maattanen L, Bangma CH, Aus G, Villers A, Rebillard X, van der Kwast T, Blijenberg BG, Moss SM, de Koning HJ, Auvinen A (2009) Screening and prostate-cancer mortality in a randomized European study. N Engl J Med 360: $1320-1328$.

Schroder FH, Hugosson J, Roobol MJ, Tammela TL, Ciatto S, Nelen V, Kwiatkowski M, Lujan M, Lilja H, Zappa M, Denis LJ, Recker F, Paez A, Maattanen L, Bangma CH, Aus G, Carlsson S, Villers A, Rebillard X, van der Kwast T, Kujala PM, Blijenberg BG, Stenman UH, Huber A, Taari K, Hakama M, Moss SM, de Koning HJ, Auvinen A (2012) Prostate-cancer mortality at 11 years of follow-up. N Engl J Med 366: 981-990.

Schroder FH, Roobol MJ (2010) ERSPC and PLCO prostate cancer screening studies: what are the differences? Eur Urol 58: 46-52.

Schroder FH, van den Bergh RC, Wolters T, van Leeuwen PJ, Bangma CH, van der Kwast TH, Roobol MJ (2010) Eleven-year outcome of patients with prostate cancers diagnosed during screening after initial negative sextant biopsies. Eur Urol 57: 256-266.

Sussman JB, Hayward RA (2010) An IV for the RCT: using instrumental variables to adjust for treatment contamination in randomised controlled trials. BMJ 340: c2073.

Thompson IM, Pauler DK, Goodman PJ, Tangen CM, Lucia MS, Parnes HL, Minasian LM, Ford LG, Lippman SM, Crawford ED, Crowley JJ, Coltman Jr. CA (2004) Prevalence of Prostate Cancer among Men with a Prostate-Specific Antigen Level $<=4.0$ ng per Milliliter. $N$ Engl J Med 350: $2239-2246$

Urban rural classification ONS (2011) http://neighbourhood.statistics.gov.uk/ or http://www.statswales.wales.gov.uk/.

Vickers AJ, Cronin AM, Bjork T, Manjer J, Nilsson PM, Dahlin A, Bjartell A, Scardino PT, Ulmert D, Lilja H (2010) Prostate specific antigen concentration at age 60 and death or metastasis from prostate cancer: case-control study. BMJ 341: c4521.

Williams N, Hughes LJ, Turner EL, Donovan JL, Hamdy FC, Neal DE, Martin RM, Metcalfe C (2011) Prostate-specific antigen testing rates remain low in UK general practice: a cross-sectional study in six English cities. BJU Int 108: $1402-1408$.

Wilt TJ (2012) The Prostate Cancer Intervention Versus Observation Trial:VA/NCI/AHRQ Cooperative Studies Program \#407 (PIVOT): Design and Baseline Results of a Randomized Controlled Trial Comparing Radical Prostatectomy With Watchful Waiting for Men With Clinically Localized Prostate Cancer. J Natl Cancer Inst Monogr 2012: $184-190$.

Zelen M (1979) A new design for randomized controlled trials. N Engl J Med 300: $1242-1245$

This work is published under the standard license to publish agreement. After 12 months the work will become freely available and the license terms will switch to a Creative Commons AttributionNonCommercial-Share Alike 3.0 Unported License. 